University of Nebraska - Lincoln

DigitalCommons@University of Nebraska - Lincoln

Faculty Publications, Department of Child, Youth, and Family Studies

Child, Youth, and Family Studies, Department of

$3-2020$

\title{
Typically Developing Preschoolers' Behavior Toward Peers with Disabilities in Inclusive Classroom Contexts
}

\author{
Soo-Young Hong \\ University of Nebraska-Lincoln, shong5@unl.edu \\ Jungwon Eum \\ University of Nebraska-Lincoln, jeum@unl.edu \\ Yanjie Long \\ University of Nebraska-Lincoln \\ Chaorong Wu \\ University of lowa \\ Greg Welch \\ University of Nebraska, gwelch@nebraska.edu
}

Follow this and additional works at: https://digitalcommons.unl.edu/famconfacpub

Part of the Developmental Psychology Commons, Family, Life Course, and Society Commons, Other Psychology Commons, and the Other Sociology Commons

Hong, Soo-Young; Eum, Jungwon; Long, Yanjie; Wu, Chaorong; and Welch, Greg, "Typically Developing Preschoolers' Behavior Toward Peers with Disabilities in Inclusive Classroom Contexts" (2020). Faculty Publications, Department of Child, Youth, and Family Studies. 275.

https://digitalcommons.unl.edu/famconfacpub/275

This Article is brought to you for free and open access by the Child, Youth, and Family Studies, Department of at DigitalCommons@University of Nebraska - Lincoln. It has been accepted for inclusion in Faculty Publications, Department of Child, Youth, and Family Studies by an authorized administrator of DigitalCommons@University of Nebraska - Lincoln. 


\title{
Typically Developing Preschoolers' Behavior Toward Peers with Disabilities in Inclusive Classroom Contexts
}

\author{
Soo-Young Hong, ${ }^{1}$ Jungwon Eum, ${ }^{1}$ Yanjie Long, ${ }^{1}$ Chaorong $\mathrm{Wu},{ }^{2}$ \\ and Greg Welch ${ }^{3}$
}

1. University of Nebraska-Lincoln, Lincoln, Nebraska, USA

2. University of Iowa, Iowa City, Iowa, USA

3. University of Nebraska, Omaha, Nebraska, USA

Corresponding author - Soo-Young Hong, Department of Child, Youth and Family Studies, College of Education and Human Sciences, University of Nebraska-Lincoln, 241 Louise Pound Hall, Lincoln, NE 68588-0366, USA, email shong5@unl.edu

\begin{abstract}
This study aimed to investigate typically developing preschoolers' behavior toward peers with disabilities in inclusive classrooms, focusing on the co-occurrence of the interactions between children with and without disabilities with various classroom contexts. Behaviors of 22 typically developing preschoolers were observed and coded on two different days in both indoor and outdoor classrooms during free play, small group activities, transitions, and meals/snack. Typically developing children interacted with peers with disabilities for a small amount of time; the interactions were significantly more likely in the outdoor classroom, in either child- or teacher-directed activities, and in play activities. There was a lack of adults' intentional scaffolding for social interactions between children with and without disabilities even when they were near the children. Activity contexts contribute to children's social behavior, and teachers need more support and training with inclusive and collaborative practices.
\end{abstract}

Keywords: preschool, inclusion, descriptive observational methods, social development, teacher intervention, eco-behavioral analysis, classroom contexts 
According to the social-cultural theory, learning and development are socially mediated (Vygotsky, 1978). Children learn concepts and skills through interactions with other members of society, especially with people more competent than themselves including parents, teachers, and peers. Without providing sufficient opportunities to interact with peers at similar ages, it would be hard to expect children to become successful members of society. During preschool years, children begin developing an awareness of others as well as their peer preferences and choices (Guralnick, Gottman, \& Hammond, 1996). In addition, they start to form more solid and reciprocal friendships with peers (Hartup \& Abecassis, 2002). Early social acceptance facilitates social competence, and social competence is frequently associated with success in school and society as well as in their peer relationships (Odom et al., 2006).

An increasing number of young children with disabilities attend an early childhood program with their typically developing peers (U.S. Department of Education, 2013). Highquality inclusive practices promote the physical and social integration of children with disabilities in classrooms and communities, so they can build a sense of community as a member of the society and form positive relationships with their typically developing peers (Guralnick, 2001; Koller, Le Pouesard, \& Rummens, 2018; Odom, Buysse, \& Soukakou, 2011). However, children with disabilities are not frequently socially included by their typically developing peers in classroom interactions especially during the time when peer interactions were more likely to occur than adult-child interactions, such as free play time (Brown, Odom, Li, \& Zercher, 1999; Guralnick, 1999; Odom, Favazza, Brown, \& Horn, 2000; Odom et al., 2004). The frequency of social interactions between children with and without disabilities was found to be very low.

Children with disabilities tended not to initiate social interactions with their counterparts (Odom et al., 2006) and may rely on typically developing children to initiate social interactions. Thus, typically developing children's behavior toward their peers with disabilities may be critical for actualizing the social integration between children with and without disabilities in inclusive preschool settings, which is one of the desired outcomes of preschool inclusion. Previous studies have examined the nature and the frequency of social participation of children with disabilities and typically developing children's attitudes toward their peers with disabilities. However, few studies have examined typically developing children's behaviors toward peers with disabilities or teachers' role in the interactions in naturalistic classroom environments.

\section{Contexts of Interactions between Children with and without Disabilities}

Characteristics of both physical and social context variables are associated with the occurrence of social interactions between typically developing children and children with disabilities (Odom et al., 2006). For example, children with disabilities who were engaged with one or more peers exhibited high-level peer play more frequently than those who engaged more with a teacher or with a group of peers with a teacher (Kontos, Moore, \& Giorgetti, 1998). In addition, child-initiated activities promoted more social interactions among children than adult-initiated activities (Tsao et al., 2008). The structure of the activities was 
also associated with the social and reciprocal engagement between children with and without disabilities in that small group activities were more likely to elicit mutual engagement between children with and without disabilities than any other structure (McCormick, Noonan, \& Heck, 1998). In addition, in some studies, children with disabilities were more engaged in peer interactions when involved in sociodramatic play and games than in more functional or constructive activities (McCormick et al., 1998), whereas others found that more structured activities were positively associated with the frequency of interactions between children with and without disabilities compared with less structured and childdirected activities (DeKlyen \& Odom, 1989). The nature and the type of the activity where children interact with one another seem to be an important factor to consider (Kontos, 1999; Kontos, Burchinal, Howes, Wisseh, \& Galinsky, 2002).

Children's awareness of the extent to which disability-related limitations influence classroom activities has also been associated with their decisions to include peers with disabilities in their play (Diamond \& Tu, 2009; Gasser, Malti, \& Buholzer, 2014). The physical demand embedded in different activity contexts affected preschool children's decisions to include the peer with a disability in activities (e.g., Diamond, Hong, \& Tu, 2008). More specifically, children without disabilities were more likely to include a hypothetical peer with a disability when the disability did not interfere or only minimally interfered with the activity (e.g., putting puzzle pieces together) than when it interfered with the proposed activity (e.g., kicking a ball). Therefore, one of the goals for this study is to investigate how classroom activity contexts are associated with typically developing children's social interactions with peers with disabilities.

\section{Teacher's Scaffolding of Social Interactions}

Teachers' intentional scaffolding helps children with disabilities participate and engage in play and learning activities with peers (Berk \& Winsler, 1995; Division for Early Childhood/National Association for the Education of Young Children [DEC/NAEYC], 2009). However, research provides conflicting findings regarding the role of adults' social prompts and intervention in the interactions between children with and without disabilities (Sontag, 1997). More specifically, children who tended to exhibit more high-level peer play were less likely to be with a teacher (Kontos et al., 1998; McCormick et al., 1998), which could be mistakenly interpreted that teacher presence or support did not promote interactions between typically developing children and children with disabilities. However, there is a possibility that teachers were more likely to initiate social interactions with a child with a disability when and if the child was not involved in social interactions with typically developing peers (Harper \& McCluskey, 2003). This interpretation is consistent with the notion proposed by social-cultural theory that development and learning is socially mediated (Vygotsky, 1978) in that teachers may intentionally prompt social interactions among children when there are immediate opportunities to develop them or when children were not engaged in peer interactions (Goble et al., 2016). Therefore, another focus of the current study is the frequency of teacher support promoting social interactions between children

with and without disabilities because the lack of interactions may have resulted from the 
fact that adults present in the classroom either missed or misused the opportunities to promote social interactions between the two groups of children (Giangreco, Edelman, Luiselli, \& MacFarland, 1997). It is critical that adults facilitate peer interactions, so children with disabilities can meaningfully engage with peers without disabilities (Feldman \& Matos, 2013). Thus, the role of teachers and other adults in the classroom also seems important in promoting the interactions between children with and without disabilities.

\section{Current Study}

Although young children have positive attitudes toward including peers with disabilities in their play and their attitudes may be associated with their actual behavior, this relation has not been systematically examined. In the current study, we investigated typically developing children's actual behavior and talk toward their peers with disabilities in naturalistic, inclusive classroom settings and examined what kinds of context variables, both indoor and outdoor, were associated with children's interactions with peers with disabilities. Our research questions are as follows:

Research Question 1: How are classroom context variables associated with the likelihood of social interactions between children with and without disabilities in inclusive preschool settings?

Research Question 2: How often do typically developing children interact with their peers with disabilities? When the interaction occurs, what is the nature of their social behaviors?

Research Question 3: When a teacher is near both children with and without disabilities, how often does the teacher support the interaction between them?

\section{Method}

\section{Participants}

Twenty-two typically developing 4- and 5-year-old children (12 girls; mean age $=52.95$ months; $S D=6.10$ ) and their teachers and parents participated in this study. More than half of the children were European American (54.5\%), and other ethnicities included African American (18.2\%), Hispanic/Latino (4.5\%), Asian/Asian American (9.1\%), and multiple ethnicities (9.1\%). Parents' education levels included some college (59.1\%), college degree $(18.2 \%)$, high school diploma (13.6\%), and master's degree (4.5\%). Parent's ethnicity included European American (59.1\%), African American (22.7\%), Hispanic/Latino (9.1\%), and Asian/Asian American (9.1\%). Eight out of 22 participating children (36.4\%) were from families living below the U.S. federal poverty level.

Participating children were enrolled in seven public preschool classrooms. The classrooms were receiving funding from multiple sources including Head Start, Title I Preschool, State funding, and special needs funding. Their mission was to help children and families become successful in a safe and inclusive environment and help everyone grow and learn together. Each class served many children from low-income families and four to 
six children with at least one identified disability (i.e., 33 children with disabilities: four in three classrooms, five in three classrooms, and six in one classroom) including developmental delay, speech language impairment, and Other Health Impairments, and this number reflects typical public early childhood classrooms in the area. Teachers reported the severity of disabilities on 22 children, and disability levels varied including mild $(n=8)$, moderate $(n=11)$, significant $(n=2)$, and severe $(n=1)$. The proportion of children with disabilities to those without disabilities was approximately 1 to 4 , and the number of children who participated from each classroom varied with a minimum of 1 to a maximum of 5 (i.e., two from three classrooms, three from one classroom, four from two classrooms, and five from one classroom). In each classroom, at least four adults were present including a head teacher, a teacher aid or an assistant teacher, an itinerant special education teacher, and a student volunteer. A speech and language pathologist occasionally visited the classroom to work with a small group of children. The head teachers had at least a BS or BA degree in Inclusive Early Childhood Education or Elementary Education/Early Childhood and 3 to 15 years of early childhood teaching experience. The special educator was in the classroom for a limited amount of time and primarily worked with children with disabilities on a one-on-one basis at a place where there were minimal interruptions from other children. As for the structure of the settings, each classroom was divided into several learning centers, a large-group activity area, and an area with multiple round tables used for small group or art activities or meals and snack. The outdoor classroom was rather small and consisted of a large play structure and several riding vehicles (e.g., trikes, wagons). Teachers brought out additional materials such as chalks and balls.

\section{Procedures}

The researchers sent a recruitment flyer to half-day inclusive preschool classrooms located in 34 public elementary school buildings in a Midwestern city, and seven classrooms located in five public schools responded to participate in this study. Once teachers provided permission to recruit families enrolled in their classroom, we asked teachers to distribute recruitment packets containing a study flyer, a parent questionnaire, a parent informed consent form, and a letter from the principal investigator that explained the study. Parents were asked to submit their signed consent form and completed questionnaire in a sealed envelope to their child's teacher, and researchers visited the classroom to pick them up from the teachers and schedule visits for observations. Out of 80 packets distributed to parents of children without disabilities, we received signed consent forms and completed parent surveys from 22 families (i.e., $27.5 \%$ return rate).

Each participating child and his or her teachers were observed in their classroom on two different days for the entire class hours. We observed children in the 2011-2012 school year to intentionally view two different seasons with multiple contexts and activities. We did not observe children during large-group circle time to avoid observing activities that are mostly teacher-directed and highly structured, which usually makes it harder to observe children's spontaneous social behaviors. Teachers' behavior and talk likely to prompt social interactions between children with and without disabilities were coded when the teacher was within $3 \mathrm{ft}$ from the target child. The 3 - $\mathrm{ft}$ criterion was used to guarantee a clear opportunity for the teacher and children to interact with one another (Kontos, 1999). 
In between the first and the second rounds of observations, a research assistant who had been to the classroom visited with each participating child to assess his or her expressive vocabulary knowledge. The assessment was conducted in a quiet corner of the child's classroom and took $5 \mathrm{~min}$ per child. In addition, teachers were asked to complete a questionnaire about their educational background and experience. Once all parts of data collection were finished, the classrooms and the participating children received a collection of picture books on children with disabilities.

\section{Measures}

\section{Observation coding systems}

We created three sets of coding systems based on information from previous studies to record specific behavior and talk of typically developing children and their teachers and to capture specific classroom contexts that co-occurred with the behavior and talk (see Table 1; DeKlyen \& Odom, 1989; Heidemann \& Hewitt, 1992; Kontos, 1999; Odom et al., 2000; Odom et al., 2006; Powell, Burchinal, File, \& Kontos, 2008; Rubin, 2001).

Table 1. Coding Systems to Record Activity Contexts and Children's Behavior and Talk

\begin{tabular}{ll}
\hline Code categories & Definition \\
\hline Activity Contexts: Setting & \\
Indoor classroom & TD is in his or her classroom. \\
Outdoor classroom & TD is in the program/center's outdoor classroom. \\
Activity Contexts: Nature of Activity & Teacher provides materials and environment, but TD makes most (or all) \\
Child-directed & choices and decisions regarding the activity and what materials to use. \\
& Teacher seems to have clear goals and steps, which he or she is using to \\
Adult-directed & direct/structure the activity. Teacher provides materials for the activity \\
& and gives directions and explicit guidance. \\
Daily routines/transitions & TD is involved in self-care, self-help, or transitions from one activity to \\
another. & \\
Activity Contexts: Type of Activity & \\
Book reading & TD is involved in a reading-related activity. \\
Large building blocks & TD is creating or constructing objects using large blocks. \\
Legos and small toys & TD is using small blocks to build objects or manipulating small toys. \\
Puzzles and shapes & TD is playing with puzzles or manipulating with shapes. \\
Games with rules & TD is playing games with rules. \\
Sensory activity & TD is playing at a sensory table/box. \\
Large motor activity & TD is involved in a large motor activity. \\
Science and nature & TD is focused on examination of an object for the purpose of obtaining \\
visual information about its specific physical properties; any activities & that involve animals, insects, and plants are included. \\
Open-ended art & ting any boundaries.
\end{tabular}


HONG ET AL., JOURNAL OF EARLY INTERVENTION 42 (2020)

\begin{tabular}{|c|c|}
\hline Code categories & Definition \\
\hline Closed-ended art & $\begin{array}{l}\text { TD is doing an art activity that is more structured and with set bounda- } \\
\text { ries. }\end{array}$ \\
\hline Dramatic play & $\begin{array}{l}\text { TD is engaged in make-believe fantasy play through transformations of } \\
\text { self or objects; role-taking and pretend play is included. }\end{array}$ \\
\hline Music and movement & $\begin{array}{l}\text { TD is singing and/or dancing to rhythmic sounds or songs or using mu- } \\
\text { sical instruments. }\end{array}$ \\
\hline Writing & TD is involved in a writing activity. \\
\hline Large play structure & TD is playing at an outdoor play structure. \\
\hline Riding vehicles & $\mathrm{TD}$ is riding vehicles. \\
\hline Other & $\begin{array}{l}\text { TD is not involved in any of the listed activities (using materials whose } \\
\text { purpose is not known to observers). }\end{array}$ \\
\hline Personal care & TD is involved in self-care with or without adult supervision. \\
\hline Meal and snack & TD is eating a meal or snack. \\
\hline Clean up & TD is putting away toys, instructional materials, furniture, or food. \\
\hline Transition activity & TD is involved in an activity that helps transition become smooth. \\
\hline \multicolumn{2}{|c|}{ Activity Contexts: Type of Social Play } \\
\hline Unoccupied or wandering & $\begin{array}{l}\text { TD has no focus or intent; TD may be staring blankly into space or wan- } \\
\text { dering with no specific purpose, only slightly interested in ongoing ac- } \\
\text { tivities; TD is not playing. }\end{array}$ \\
\hline Onlooker & $\begin{array}{l}\text { TD watches activities of others but does not enter the activity for the en- } \\
\text { tire interval ( } 15 \mathrm{~s}) \text {. TD may offer comments or laugh but does not become } \\
\text { involved in the actual activity. }\end{array}$ \\
\hline $\begin{array}{l}\text { Parallel play or on-task } \\
\text { behavior }\end{array}$ & $\begin{array}{l}\text { TD is engaged in an activity beside but not interacting with other chil- } \\
\text { dren, usually present within a distance of } 3 \mathrm{ft} \text { or less; TD is playing next } \\
\text { to another child with similar materials. }\end{array}$ \\
\hline Engaged with $\mathrm{T}(\mathrm{s})$ only & $\begin{array}{l}\text { TD is engaged with adults only; no interactions are observed between } \\
\text { TD and a peer nearby. }\end{array}$ \\
\hline Engaged with $1 \mathrm{~Pa}$ & TD is engaged with 1 peer. \\
\hline Engaged with Ps onlya & $\begin{array}{l}\text { TD is engaged with } 2 \text { or more peers; no interactions are observed be- } \\
\text { tween TD and adult(s). }\end{array}$ \\
\hline Engaged with $\mathrm{T}(\mathrm{s})$ and $1 \mathrm{~Pa}$ & TD is engaged with adult(s) and 1 peer. \\
\hline Engaged with $\mathrm{T}(\mathrm{s})$ and $\mathrm{Ps}^{\mathrm{a}}$ & TD is engaged with adult(s) and 2 or more peers. \\
\hline Without materials or toys ${ }^{a}$ & TD is engaged with adult(s) or peer(s) without any materials or toys. \\
\hline \multicolumn{2}{|c|}{ Child's Behavior and Talk: Nature of Peer Interaction } \\
\hline Simple acknowledgment & $\begin{array}{l}\text { TD provides or receives simple acknowledgments; supports peers' state- } \\
\text { ment; gains attention of peer; shows pride to peer. }\end{array}$ \\
\hline Shows interests in peer & $\begin{array}{l}\text { TD imitates a peer's verbalization or action; physically follows a peer; or } \\
\text { shows interest in what the peer does; initial stage of engagement. }\end{array}$ \\
\hline Joins and/or invites peer & $\begin{array}{l}\text { TD joins peer (who is alone) in a specific activity or invites peer to an ac- } \\
\text { tivity; beginning/initial stage of play. }\end{array}$ \\
\hline Ask simple questions & $\begin{array}{l}\text { TD asks a question to another peer; the question should not be a help- } \\
\text { seeking question. }\end{array}$ \\
\hline
\end{tabular}




\begin{tabular}{ll}
\hline Table 1. Continued & Definition \\
\hline Code categories & TD describes what he or she sees, hears, wants, needs, and/or does; \\
pointing to what he needs or wants can be a nonverbal description of his \\
needs/wants. \\
TD is actively engaged in sustained and reciprocal interactions with \\
peer(s) with or without play materials; neither party is leading nor being \\
led; neither party is helping nor being helped; children are equally en- \\
gaged in an activity or an interaction. \\
TD provides explanation and/or information for a peer; provides help to \\
a peer; offers help or shares materials that he or she was using; models \\
behavior; or indirectly helps peer accomplish or complete a task; helps \\
when help seems truly needed. \\
TD seeks or receives explanation and/or information from a peer; re- \\
quests or receives help from the peer. \\
TD is leading a peer in an activity. \\
TD is being led by peer in an activity. \\
TD is expressing emotions. \\
Is led by peer (passive) \\
Expresses emotions \\
Competes with peer
\end{tabular}

Note: $\mathrm{TD}=$ typically developing child (target child); $\mathrm{T}=$ teacher or adult; $\mathrm{P}=$ peer; $\mathrm{AA}=$ adult's attention; $\mathrm{ME}=$ materials or equipment.

a. Also coded whether the TD was interacting with peer(s) with disabilities (PWD) or another TD.

For "Activity Contexts," our coding categories included Setting (indoor, outdoor), $\mathrm{Na}$ ture of Activity (adult-directed, child-directed, daily routine, and transition), Type of Activity (e.g., books, sensory, small toys, large building blocks, dramatic play), Group Composition (e.g., with one adult and one peer, with peers), and Type of Social Play (e.g., engaged with one peer, engaged with adult(s) and peer). We clearly defined that the Type of Activity should be focused on what the child was actually doing rather than on the area of the classroom in which the child was. For example, when a child was engaged in a dramatic play while she was in the block area, the behavior was coded as dramatic play rather than block play.

For "Child's Behavior and Talk," the Nature of Peer Interaction (e.g., asks simple questions, helps, expresses emotions, seeks help, refuses, or ignores) was coded in each interval. When we developed these codes, we focused specifically on social nature of the behavior excluding behaviors with other foci or intentions. The codes for Nature of Peer Interaction were not mutually exclusive, so we coded all categories observed during each interval.

For "Teachers' Behavior and Talk," codes included Teaches or Models (explains or models to the typically developing children how to interact with a peer); Participates (facilitates interactions between the typically developing children and the peer by becoming an active 
participant in children's play or conversation); Promotes Communications (explicitly encourages or instructs child to use language); Redirects (directs the typically developing children to interact with a peer or redirects them to another activity, area, or behavior); Praises (expresses praise, appreciation, or satisfaction to the typically developing children or his or her socially competent behavior); Comments/Suggests/Questions (makes suggestions, comments, or questions, from outside the children's play, about child's play, or other activity); Refers to a Peer (refers the former to help or to be helped by the latter, by pointing out that a peer needs someone to play with, or pointing out a peer as a model); Interprets (explicitly interprets to the typically developing children the meaning, intent, or perspective on behalf of the peer); Disciplines (provides corrections to inappropriate or negative behavior displayed by the typically developing children toward the peer; may restate class rules); Monitors (visually attends to the child/group; with no direct contact/involvement in the typically developing children's activity). These behaviors were coded only when the teacher used one or more of these strategies to promote social interactions. The codes for teachers' behavior and talk were not mutually exclusive, so we coded all categories observed during each interval.

We used the time-sampling observational method to code classroom contexts and behavior and talk of participating children and teachers. We first observed participating child's behavior and talk, teachers' behavior and talk, and classroom contexts for each observational interval $(20 \mathrm{~s})$ and then coded the observation for the following $30 \mathrm{~s}$. This cycle of 20-s observation and 30-s coding continued throughout the observation of each child. Previous research used the similar time-sampling method for the same purpose (Early et al., 2006; Kontos, 1999), and, according to our piloting of different lengths of time, $20 \mathrm{~s}$ provided proper amount of information regarding children's activities and interactions in comparison with 10, 15, or $30 \mathrm{~s}$, and we needed at least $30 \mathrm{~s}$ to accurately record observed behaviors and interactions. Each child was observed for approximately $6 \mathrm{hr}$ on two different days which enabled us to collect up to $360 \mathrm{~min}$ of data per child. Due to various reasons (e.g., some children being dropped off late and picked up early, extended large-group activities), however, the number of intervals during which each child was observed ranged from 172 to $353 \mathrm{~min}(M=266.14 ; S D=46.68)$.

Three research assistants were trained to use these coding systems using four 1-hr videotapes of a group of preschoolers at a university laboratory school. Training videos included a variety of contexts and activities, such as indoor and outdoor free play, small group activities, meals, snacks, and transitions. After several sessions of thorough discussion and practice coding, we reached $85 \%$ to $100 \%$ agreements on all codes before beginning the data collection. All researchers met to check inter-coder reliability every 3 weeks with two 20-min videotapes with various contexts to ensure that the inter-coder reliability stayed at least at $80 \%$ for all categories. When there were disagreements during reliability checks, we stopped data collection and met to discuss those particular codes and resolved the issues. The reliability check could not be conducted in the classrooms where the actual data were collected due to the time restraints of the data collectors and the teachers' request not to overcrowd their already crowded classroom. The average percent agreement ranged from $75 \%$ (Nature of Peer Interaction) to $100 \%$ (Setting, Nature of Activity). 


\section{Vocabulary knowledge}

We assessed children's vocabulary knowledge using the Woodcock-Johnson III Picture Vocabulary Test. The administrator asked the child to label each picture presented to them. It took about $5 \mathrm{~min}$ to complete the assessment with each child with varying ability levels. This variable was used as a child-level covariate in the analysis to control for the effect that children's language may have on their social interactions. In the analysis, the standardized score, $t$, was used $(M=50 ; S D=10)$.

Parent and teacher questionnaires

Parents were asked to complete a questionnaire regarding their education level and their child's age, gender, and ethnicity. A dichotomous variable was created for child's ethnicity, as the majority of the participating children were European American ( $1=\mathrm{EA} ; 0=$ nonEA). Mothers' educational level was coded as $1=\mathrm{BA}$ degree or $0=$ no BA degree. Teachers provided information about their education level, years of teaching experience, and the numbers of children with disabilities and adults in the classroom.

\section{Study Variables}

Frequencies and percentages were calculated for each of the individual behavior, talk, and context variables. Using the frequency information as well as conceptual meaning of each code, we created composite variables to be entered in the main analyses. As for Setting, indoor versus outdoor classroom was used in the analysis. As for Nature of Activity, childdirected, adult-directed, and daily routines were used. In terms of Type of Activity, which was defined as the activity in which the typically developing target child was participating, three categories were created: Academic activity (e.g., book, science); Play activity (e.g., large building blocks, sensory, Legos, dramatic, large motor, riding); and Transitions and routines (e.g., meal, clean-up, transition) (Powell et al., 2008). Codes for typically developing children's behavior and talk toward peers with disabilities were collapsed into seven composite variables on the basis of their conceptual congruence: (a) active engagement (joins or invites peer, asks simple questions, describes, actively engaged, follow the game rule); (b) low level-positive (simple acknowledgment, shows interest in peer); (c) helping or leading (helps [active], leads peer [active]); (d) expressing emotions; (e) being assertive; (f) low level-negative (competes with peer for adult's attention or materials, refuses, or ignores peer); and (g) being helped or led (seeks or receives help-passive; is led by peerpassive). Codes for teacher talk and behavior were combined to create one dichotomous variable that indicates whether the adult provided support for children with and without disabilities to interact with each other when the adult was close to them. Individual codes could not be used due to the low frequency of teachers' behavior and talk even when the teacher was within $3 \mathrm{ft}$ from the target child and his or her peer(s) with disabilities (i.e., 101 out of 2,750 intervals; $3.67 \%$ ). Out of 101 intervals, the teacher initiated the interactions during 78 intervals (cf. response $=23$ intervals).

The dependent variable, Interactive Play [IP] with Peers with Disabilities, was created by combining intervals that included the interactive nature of play between children with and without disabilities (i.e., IP with one peer with a disability, IP with peers with disabilities, IP with one adult and one peer with a disability, IP with one adult and multiple peers with 
disabilities, and PI with a peer with disabilities without play materials) and coded as 1 (interaction with peer(s) with disabilities) or 0 (no interaction). Finally, we included child's gender, ethnicity, and parent education as control variables and children's expressive language skills as a covariate in the analyses because of the known associations of family and demographic factors and children's language skills with children's social competence.

\section{Results}

Children were interacting with one or more peers for $41.96 \%$ of the intervals and with children with disabilities for approximately $9.49 \%$ of the intervals $(n=2,457$ and 555, respectively), which means that, of the $41.96 \%$ of intervals with peer interactions, $22.59 \%$ contained interactions with a peer with disabilities. Most observations were conducted indoors ( $85.82 \%$ of the total number of intervals), and the nature of the half of the activities was child-directed (50.21\%) followed by transitions and routines $(38.60 \%)$. About $44 \%$ of the intervals were devoted to play activities in comparison with the $9 \%$ of the intervals spent on more academic content, such as reading, writing, science, and music. Activities related to transitions and routines took up about $47 \%$ of the entire observation intervals (see Table 2). The frequencies of intervals where social interactions occur did not vary between the Fall and the Spring observations (i.e., $n=296$ vs. 259, respectively), which indicates that the duration of relationships did not make a difference in the frequency of social interactions. Therefore, we did not include the timing/season of the observations in the analyses.

\section{Contexts Where Children Interacted With Peers with Disabilities}

We conducted two multilevel logistic regression analyses. Our data were structured so that observations were nested within children and that within-subject and between-subject observations were evident. Thus, the data contained within-subject and between-subject observations. Multilevel modeling approach (Bryk \& Raudenbush, 1992) was selected, choosing SAS Proc Glimmix for its flexibility in modeling generalized linear mixed model (GLMM). Specifically, a logistic link was used because the outcome variables were dichotomous. The probability of answering "yes" (rather than "no") was modeled. A random intercept was included for each model, under the assumption that individuals differ at their logit at the reference group. Containment method was selected as the method for computing the denominator degrees of freedom for the tests of fixed effects. Residual pseudolikelihood with a subject-specific expansion was chosen as the estimation technique. 


\begin{tabular}{|c|c|c|}
\hline Categories and variables & Frequency & Percentage \\
\hline TD's Interaction with PWD (DV) & $(N=5,855)$ & \\
\hline No & 5,300 & 90.52 \\
\hline Yes & 555 & 9.48 \\
\hline \multicolumn{3}{|l|}{ Activity Setting } \\
\hline Outdoor & 830 & 14.18 \\
\hline Indoor $^{\mathrm{a}}$ & 5,025 & 85.82 \\
\hline \multicolumn{3}{|l|}{ Nature of Activity } \\
\hline Child-directed & 2,937 & 50.21 \\
\hline Adult-directed & 655 & 11.20 \\
\hline Transitions/Routines ${ }^{\mathrm{a}}$ & 2,258 & 38.60 \\
\hline \multicolumn{3}{|l|}{ Type of Activity } \\
\hline Academic & 519 & 8.86 \\
\hline Play $^{\mathrm{a}}$ & 2,566 & 43.82 \\
\hline Transitions/Routines & 2,769 & 47.29 \\
\hline Child's Behavior and Talk ${ }^{b}$ & $(n=555)$ & \\
\hline Active engagement & 323 & 58.20 \\
\hline Low level-positive & 124 & 22.34 \\
\hline Helping or leading & 109 & 19.64 \\
\hline Expressing emotions & 94 & 16.94 \\
\hline Being assertive & 34 & 6.13 \\
\hline Low level-negative & 14 & 2.52 \\
\hline Being helped or led & 11 & 1.98 \\
\hline \multicolumn{3}{|l|}{ Teachers' Behavior and Talk } \\
\hline $\mathrm{T}$ present within $3 \mathrm{ft}$ from child & $2,750(N=5,855)$ & 47.00 \\
\hline $\mathrm{T}_{\text {promoting social interactions }}{ }^{\mathrm{c}}$ & $101(n=2,750)$ & 3.67 \\
\hline $\mathrm{T}$ initiating social interactions $\mathrm{s}^{\mathrm{c}}$ & $78(n=101)$ & 77.23 \\
\hline
\end{tabular}

Note: $\mathrm{TD}=$ typically developing child; $\mathrm{PWD}=$ peer(s) with disabilities; $\mathrm{DV}=$ dependent variable; $\mathrm{T}$ = teacher/adult

a. Reference.

b. Codes are not mutually exclusive.

c. Coded only when a teacher/adult was present within $3 \mathrm{ft}$ from the target child and PWD.

The dependent variable was a dichotomous variable that represented whether or not the target child was interacting with at least one peer with a disability (i.e., interaction vs. no interaction). Independent variables were also dichotomous variables including indoor (vs. outdoor) and daily routines and transitions (vs. child-directed or adult-directed) for our first model and indoor (vs. outdoor) and play activities (vs. academic activities or transitions/routines) for our second model. We controlled for child age, child gender, child ethnicity, child language, and parent education (child level) and by adding them to the models before the main independent variables (behavior level) were entered. We decided to develop two different models to answer the first question rather than including all independent variables in one model because of the interdependence between two coding categories, Type of Activity and Nature of Activity. More specifically, if the Nature of Activity 
was coded as daily routines and transition, only one from four codes included in Type of Activity can be coded (i.e., personal care, meal snack, clean up, or transition activity). The equation for Model 1 is shown below, where $i$ is for the $i$ th person and $t$ is for the $t$ th interval. Model 2 is similar to Model 1 except that Type of Activity replaces Nature of Play in the model. The estimates for both models are shown in Tables 3 and 4 .

Level 1: For the $i$ th child at the $t$ th interval/behavior, the probability of observing the interaction between the target child and a peer with disabilities is as follows:

$$
P\left(Y_{t i}=1\right)=\frac{e^{\beta_{0_{i}}}}{1+e^{\beta^{0_{i}}}}
$$

Level 2: For the $i$ th child, the second-level equation is as follows:

$$
\begin{aligned}
\beta_{0 i}= & \gamma_{00}+\gamma_{01}\left(\text { Indoor }_{i}\right)+\gamma_{02}\left(\text { NatureOfPlay }_{i}\right)+\gamma_{03}\left(\text { ChildAge }_{i}\right) \\
& +\gamma_{04}\left(\text { ChildGender }_{i}\right)+\gamma_{05}\left(\text { ChildExpVocab }_{i}\right)+\gamma_{06}\left(\text { ChildEthnicity }_{i}\right) \\
& +\gamma_{07}\left(\text { ParentEducation }_{i}\right)+U_{0 i}
\end{aligned}
$$

where $U_{0 i} \sim N\left(0, \sigma^{2}\right)$.

Analyses revealed that typically developing children were more likely to interact with at least one peer with disabilities in an outdoor classroom than in an indoor classroom, $t(5,251)=3.18, p=.002$, in adult-directed or child-directed activities rather than during daily routine and transition times, $t(5,247)=7.19, p<.0001 ; t(5,247)=5.93, p<.0001$, respectively, and in play activities rather than during academic activities or during transition and routine times, $t(5,251)=-2.99, p=.003 ; t(5,251)=-7.92, p<.0001$, respectively (see Table 3 ).

Table 3. Estimates and Standard Errors from Analyses of Interactive Play with Peers in Model 1

\begin{tabular}{lccrrc}
\hline Effect & Estimate & $S E$ & $d f$ & $t$ value & $\operatorname{Pr}>|t|$ \\
\hline Intercept & -0.2554 & 2.7247 & 14 & -0.09 & .9266 \\
Indoor (reference = outdoor) & 0.2366 & 0.1335 & 5,247 & 1.77 & .0763 \\
Nature of Activity: routines/transitions & (reference = routines/transitions) & & & \\
$\quad$ (Teacher-directed) & 0.8643 & 0.1202 & 5,247 & 7.19 & $<.0001$ \\
$\quad$ Child-directed) & 0.9713 & 0.1638 & 5,247 & 5.93 & $<.0001$ \\
C age & -0.03752 & 0.05353 & 5,247 & -0.70 & .4834 \\
C gender (reference = male) & -0.3679 & 0.5641 & 5,247 & -0.65 & .5143 \\
C vocabulary knowledge & -0.05963 & 0.1126 & 5,247 & -0.53 & .5963 \\
C ethnicity (reference = White) & -0.3457 & 0.4726 & 5,247 & -0.73 & .4645 \\
P education (reference = BS/BA degree) & 0.6392 & 0.5896 & 5,247 & 1.08 & .2783 \\
\hline
\end{tabular}

Note: $\mathrm{C}=$ child; $\mathrm{P}=$ parent 
Table 4. Estimates and Standards Errors from Analyses of Interactive Play with Peers in Model 2

\begin{tabular}{lccccc}
\hline Effect & Estimate & $S E$ & $d f$ & $t$ value & $P r>|t|$ \\
\hline Intercept & 0.5129 & 2.6047 & 14 & 0.20 & .8467 \\
Indoor (reference = outdoor) & 0.4044 & 0.1273 & 5,251 & 3.18 & .0015 \\
Type of Activity (reference = play) & & & & & \\
$\quad$ (Academic) & -0.6251 & 0.2092 & 5,251 & -2.99 & .0028 \\
$\quad$ (Routines/Transitions) & -0.8391 & 0.1059 & 5,251 & -7.92 & $<.0001$ \\
C age & -0.03582 & 0.05117 & 5,251 & -0.70 & .4839 \\
C gender (reference = male) & -0.2948 & 0.5390 & 5,251 & -0.55 & .5845 \\
C vocabulary knowledge & -0.05401 & 0.1077 & 5,251 & -0.50 & .6160 \\
C ethnicity (reference = White) & -0.3186 & 0.4516 & 5,251 & -0.71 & .4805 \\
P education (reference = BS/BA degree) & 0.6094 & 0.5636 & 5,251 & 1.08 & .2796 \\
\hline
\end{tabular}

Note: $\mathrm{C}=$ child; $\mathrm{P}=$ parent

\section{Nature of Social Behaviors When Interactions Occurred}

Overall, there were infrequent interactions between children with and without disabilities (555 intervals; $9.48 \%$ of the intervals observed). However, when interactions occurred, the most frequent type of interaction was active engagement $(58.20 \%)$, which means that the typically developing child was actively engaged in reciprocal and sustained interactions with a peer with a disability. In addition, most interactions were positive with a few negative behaviors observed. Typically developing children were helping or leading the peer with disabilities for approximately $20 \%$ of the intervals, expressing positive emotions for about $17 \%$ of the intervals and were being helped or led by a peer with a disability for about $2 \%$ of the intervals. Typically developing children were sometimes acting assertively by overly helping or leading a peer with a disability $(6.13 \%)$ which was coded separately from "helping or leading."

\section{Teachers' Behavior and Talk When Near the Children}

Frequencies of the teacher talk and behavior variables revealed that the teacher was near children with and without disabilities for approximately $47 \%$ of the intervals (2,750 out of 5,855 observation intervals). We found out that 319 out of these 2,750 intervals overlapped with the 555 intervals where children interacted with peers with disabilities $\left(\chi^{2}=27.19, p<.001\right)$ although this does not provide the information about what was happening in the preceding interval. Of the 2,750 intervals, however, teachers were actually intervening the interactions between children with and without disabilities for about $3.67 \%$ of the intervals (101 out of 2,750 intervals), and, during most of the intervals, the teacher initiated the interactions as opposed to responding to the social behaviors that the target child was exhibiting (78 out of 101 intervals).

\section{Discussion}

Although typically developing children play an important role in actualizing the social integration in inclusive early childhood settings, their behavior and talk have not been systematically examined. The current study investigated typically developing preschoolers' 
social behavior and talk toward their peers with disabilities in inclusive classrooms. The target of the observations, therefore, was on those without disabilities. In addition, although previous research focused on the lack of interactions initiated or responded to by children with disabilities, we focused on contexts where the interactions between children with and without disabilities were likely to occur. This is one of the unique contributions of this study because the detailed observations of typically developing children in inclusive classroom settings would inform researchers and practitioners in developing an intervention or professional development program that involves naturalistic contexts and activities as a venue for promoting social interactions between children with and without disabilities.

\section{Contexts Where Children Interacted with Peers with Disabilities}

Children with and without disabilities had minimal interactions throughout the day as found in previous literature on preschool inclusion (e.g., Odom et al., 2004, 2006). Our main findings conclude that children without disabilities were more likely to interact with peers with disabilities: (a) outdoors than indoors, (b) during child-directed or adult-directed activities rather than transitions and routines, and (c) during play activities rather than either academic activities or transitions or routines.

\section{Indoors versus outdoors}

Young children's social interactions have been studied both indoors and outdoors. Although indoor space might increase the possibility for children to bump into their peers due to its higher social density than outdoor contexts, several researchers primarily studied children during outdoor recess time, rationalizing that social interactions were encouraged more frequently outdoors than indoors (Fanger, Frankel, \& Hazen, 2012; Li, Hestenes, \& Wang, 2016). It may be possible that typically developing children might have been more accepting of their peers with disabilities outdoors than indoors because an outdoor context provides an extended interactive space and allows more large-scale play that can include more peers, such as playing tag and climbing on a large play structure. Others also found that outdoor games encouraged children's social interactions and physical activity (Verhaegh, Soute, Kessels, \& Markopoulos, 2006) and that a more complex level of play interactions (i.e., interactive and dramatic play) between different age groups were more likely to occur in the outdoor classrooms than in the indoor ones (Shim, Herwig, \& Shelley, 2001). Studies have examined the demands of physical activity contexts affecting children's decision to include or not to include a peer with a physical disability (e.g., Diamond \& Tu, 2009). The hypothetical child in a wheelchair used in Diamond and Tu (2009) study was unlikely to be included in physically demanding activities although included in physically less demanding activities. In the current study, participating classrooms included children with various disabilities at different levels, and outdoor classrooms provided options other than a play structure requiring various motor skills. Little research investigated the affordances that outdoor classroom environment might provide children with various activities including physical and nonphysical. Outdoor contexts seem to encourage interactions among young children no matter what levels of abilities they have; therefore, further investigation of outdoor environment in relation to children's inclusive interactions is needed. 


\section{Nature of Activity}

The activities that were either child-directed or teacher-directed were more likely to elicit social interactions as compared with transitions and routines. This result is partly consistent with that of DeKlyen and Odom (1989), where the extent to which the teacher structured the activities was positively associated with the frequency of peer interactions. We also found a similar positive association between child-directed activities and social interactions as in Booren, Downer, and Vitiello (2012), where children were more engaged with peers during child-directed activities than transitions and routines. Our speculations for the lack of social interactions during transitions and routines include that, for task-related activities, children may exhibit more on-task behavior than interactive play as found in several other studies (e.g., McWilliam, Scarborough, \& Kim, 2003).

\section{Type of Activity}

Play activities were better contexts for social interactions between children with and without disabilities as compared with academic activities or transitions and routines. This finding is consistent with that of Odom and Peterson (1990) and is somewhat similar to what Kemp, Kishida, Carter, \& Sweller (2013) and Innocenti et al. (1986) found, where more social interactions were exhibited during free play time than other times of the day. However, there is room for further discussion. Kemp et al. (2013) made an assumption that free play activities would all be child-directed activities. In the current study, we emphasized that the Type of Activity (e.g., open-ended art, dramatic play, science, book-reading) should be separately and independently coded from the Nature of Activity (e.g., child-directed, adult-directed, routines) except for transitions and daily routines because, even during free play time, adult-directed interactions can happen. In a high-quality preschool classroom, free play (or center) time usually consists of both play activities and academic activities. Therefore, the current study adds more specifics to the previous studies in terms of the contexts that were more likely to facilitate social interactions. That is, whether those social interactions happened during free play time or other times of the day, play activities were the context where social interactions between children with and without disabilities were more likely to occur than the other contexts.

Play is an important context where children learn social knowledge and interpersonal skills including collaboration, negotiation, entry or invitation to peer play, and pretend play (e.g., Schuler \& Wolfberg, 2000). Researchers have found that children with disabilities were more likely to be engaged in peer interactions when involved in sociodramatic play and games than in more functional or constructive activities (DeKlyen \& Odom, 1989; McCormick et al., 1998). The finding from the current study seems to support this result because play activities rather than academic activities or transitions and routines would afford more opportunities for sociodramatic play and collaborative games. Activities with specific academic content, however, can also support the interactions between children with and without disabilities. A short-term longitudinal case study with a group of preschool children with and without disabilities showed a possibility by using inclusive writing communities where children sit together to "create marks, drawings, words, and stories while talking and listening to each other" (McCloskey, 2012, p. 52). However, our 
finding suggests that more free play which in turn supports play-based learning may benefit social interactions between children with and without disabilities.

\section{Nature of Social Behaviors When Interactions Occurred}

Although typically developing children were engaged in interactions with peers with disabilities for only $10 \%$ of the observed intervals, the observed social interactions may provide us with better ideas regarding how the children actually interacted with one another. The positive finding is that the typically developing children were actively engaged with peers with disabilities when an interaction occurred, which means that their interactions were reciprocal and sustained for the entire interval. Participating children and their peers with disabilities were playing together (e.g., play games) and sharing materials and conversations. They shared positive emotions, and typically developing children helped and were helped by a peer with a disability. Most social interactions were positive in nature when they occurred. These indicators of behavioral intentions seem to reflect young children's generally positive attitudes toward people with disabilities found in previous studies (e.g., Hong, Kwon, \& Jeon, 2014), although the positive attitudes did not seem readily connected to the frequency of their social behaviors and interactions.

In addition, children enrolled in an inclusive preschool expressed an increased sensitivity and responsiveness to others (Diamond \& Carpenter, 2000; Peck, Carlson, \& Helmstetter, 1992). The current study extended these results in that children without disabilities were sometimes helped and led by a peer with a disability, although the frequency was very low. The helping behavior was coded as "help" only when it was a true helping behavior compared with being overly helpful (i.e., coded as "being assertive") to ensure that the unnecessarily helpful behavior was not seen as positive social behavior. An unclear part is, however, whether helping behavior was elicited by an adult (e.g., asking a peer with a disability to help the child without disabilities) or exhibited spontaneously by the child. Because it is possible that children's interpretation of their own behavior does not always match with adult assessments, it would be critically important to further examine how typically developing children define and interpret helping behavior and use it to interact with peers with disabilities and how that supports or inhibits the development of children with disabilities.

\section{Teachers' Behavior and Talk When Near the Children}

Overall, there were many opportunities available for teachers to intentionally promote social interactions between children with and without disabilities because an adult was present within $3 \mathrm{ft}$ of both children with and without disabilities for approximately $47 \%$ of the intervals observed. Despite the large number of intervals in which teachers had access to both groups of children, teachers exhibited behavior and talk to elicit or sustain social interactions in only $3.67 \%$ of those intervals with opportunities. Our speculation is that a teacher who was close to a child with a disability might have focused mostly on working with that child (e.g., working on specific skills) without involving other children in the same area, especially if that adult was a special education teacher, speech and language pathologist, or an early intervention specialist. However, this result provides early childhood professionals with an opportunity to reflect more deeply on the important goal of 
inclusion and the issue around partnerships between early childhood educators and early childhood special educators serving the same group of young children and families. Early childhood communities have already recognized a gap in professional development opportunities provided to early childhood teachers on working with children with varying levels of abilities (Wei, Darling-Hammond, \& Adamson, 2010). In addition, teachers' attitudes toward disabilities and inclusion were positively and significantly associated with their training and prior experience working with children with disabilities (Kwon, Hong, \& Jeon, 2017). All these findings call support for greater teacher training focused on inclusive and collaborative early childhood teaching practices.

\section{Limitations and Future Directions}

First, in the current study, the types and the severity of disabilities were not taken into account in analyzing the likelihood of social interactions between children with and without disabilities. Typically developing children tend to be more sensitive to the physical demand of different activities when they interact with peers with disabilities (Diamond \& Hong, 2010); therefore, the types and the severity of disabilities that peers have may affect the decisions that typically developing children make. The evidence supporting the association of disability types with the amount of interactive play include McGaha and Farran's (2001) study where interactive play increased for children without visual impairments but decreased for children with visual impairments in the outdoor space compared with indoor space. However, more than $80 \%$ of children with disabilities in the current study had mild or moderate disabilities and either developmental delays or speech-language impairments. Only a few had significant or severe disabilities. Thus, typically developing children's behaviors toward peers with disabilities might have looked different from the plausible case of having children with various disabilities in the classroom. In addition, the gender of children with disabilities was not taken into account in the current study although we know that preschool children tend to show their preferences for same-sex playmates at a young age (e.g., Maccoby, 1988). In future studies, the characteristics of children with disabilities would need to be examined in studies of peer interactions between children with and without disabilities.

Second, in the current study, target children's vocabulary knowledge was added to the model as a covariate rather than their general levels of social skills. Although children's language skills have been associated with children's social interactions and communications (e.g., Craig-Unkefer, \& Kaiser, 2002), it may be more helpful to include a measure of social competence as a covariate especially due to significant associations often found between children's social competence and their social interactions in the classroom (Diamond, Hong, \& Baroody, 2008).

Third, classroom-level predictors, such as teacher training and classroom environment, were not taken into account in the current study due to the small sample size. A larger classroom-level sample with a sufficient number of children in each classroom sample would enable us to examine how teacher practices and experiences are associated with children's social interactions with peers with disabilities. For example, predictors such as the assigned and perceived role of the teachers/adults present in the classroom (e.g., lead 
teacher, special education teacher, and paraprofessional) and their experiences in terms of their pre-service education, in-service training, and their attitudes toward specific classroom practices may eventually affect their behaviors in the classroom. In the current study, any adult present near the children with and without disabilities was considered a teacher whose behavior was coded. This was based on the belief that any adults in the classroom should be responsible for the promotion of effective social interactions among children. However, we know from research that the level of education and in-service training makes a difference in terms of how the interactions work (Barnett, 2004; Bueno, Darling-Hammond, \& Gonzales, 2010; Early et al., 2006). Therefore, it would benefit the field to take a closer look at the different characteristics of each classroom and how those classroom characteristics are associated with the frequency and the nature of social interactions between children with and without disabilities. It would also be beneficial to investigate what the teacher was doing in the intervals immediately preceding when the two children interacted and also to examine the contexts immediately preceding when the children interacted. This idea was briefly introduced in the "Discussion" section where the contingent responsivity concept was introduced; however, this analysis could not be conducted using the current data set because of the infrequent number of intervals of teacher behavior and the sparse occurrences that prevented us from examining the lagged effects of teachers' influences on children's behavior.

Fourth, teachers' behavior and talk may need to be analyzed and interpreted in relation to the child's behavior and talk. Not all teachers' prompting seems helpful or effective. Rather, it seems more important to consider the timing and the specific interactional contexts in promoting social interactions between children with and without disabilities. Although the likelihood was very low that children without disabilities were interacting with children with disabilities, it is possible that, at some point, teachers must have waited a bit longer until intervening in their social interactions without prompting their behavior and talk. This becomes an even more plausible explanation for the lack of teacher intervention as we found in our data that most teachers' prompting, if any, was to initiate rather than to respond to a child's behavior and talk. This analysis needs further attention. A larger number of settings and classrooms/teachers may make it more meaningful to examine teachers' behavior and talk in relation to child's behavior and talk. It is also critical to examine the association among teachers' attitudes toward inclusion, their educational and training experiences, and their practices promoting social interactions between children with and without disabilities (Hsien, Brown, \& Bortoli, 2009; Jeon \& Peterson, 2003).

Finally, previous studies have examined preschool children's attitudes toward peers with disabilities that helped us reflect on how children made inclusion and exclusion decisions. The current study shows the context where these children were more likely to interact with peers with disabilities (i.e., outdoors than indoors; play activities than academic activities or transitions/routines; teacher- or child-directed activities than transitions/routines). Attitudes are associated with behaviors in complicated ways (Yu, Ostrosky, \& Fowler, 2012) as represented through three interconnected dimensions: cognitive (beliefs and understanding), affective (feelings and emotional reactions), and behavioral (a predisposition to act in a certain way), which contributes to the exhibited behavior (Ajzen, 1988). A study 
that combines the investigation of behaviors and multiple dimensions of attitudes will provide a clearer picture of the important factors associated with the social interactions between children with and without disabilities in inclusive preschool classrooms. Some direct discussion with the children themselves about their choices and observations and individual interviews and reflections with the teachers about their choices, opportunities, and practices would enrich the findings from the current study.

\section{Implications for Practice}

In the current study, we found that children were more likely to socially interact with peers with disabilities in outdoor spaces (vs. indoor spaces) and during play activities (vs. academic activities). It might be beneficial to intentionally promote social interactions in those contexts and examine whether the contexts make a difference in children's social interactions. In addition, transitions and routines may not be the best context to promote social interactions in. It seems more likely for social interactions to occur during activities that either children or teachers direct and that involve active play and/or instruction. Furthermore, our findings about teachers' behavior and talk provide us with an opportunity to think more about the effect of training on how frequently or effectively teachers interact with children to support and scaffold their peer interactions. All adults in the classroom were expected to interact with all children at some point during the class time to intentionally help children build relationships and participate in interactions with one another. A constant reminder and training about building a strong interdisciplinary team of all early childhood professionals may promote more effective early childhood inclusive instructional methods and enhance the interactions between children with and without disabilities. Finally, the value of inclusive settings is to support all children. It is important to have typically developing children experience interactions with children who have different levels of abilities and vice versa while creating a truly beneficial educational experience for everyone. Therefore, it would be critical for all early childhood teacher preparation programs to utilize evidence-based professional standards (e.g., NAEYC and CEC/DEC) to strengthen the quality of early childhood workforce prepared to work with all children (Guralnick \& Bruder, 2016).

Declaration of Conflicting Interests - The author(s) declared no potential conflicts of interest with respect to the research, authorship, and/or publication of this article.

Funding - The author(s) received no financial support for the research, authorship, and/or publication of this article.

\section{References}

Ajzen, I. (1988). Attitudes, personality, and behavior. Milton Keynes, UK: Open University Press.

Barnett, W. S. (2004). Better teachers, better preschools: Student achievement linked to teacher qualifications. Preschool Policy Matters, 2. New Brunswick, NJ: National Institute for Early Education Research. Retrieved from http://nieer.org/policy-issue/policy-brief-better-teachers-better-preschools-studentachievement-linked-to-teacher-qualifications 
Berk, L. E., \& Winsler, A. (1995). Scaffolding children's learning: Vygotsky and early childhood education. Washington, DC: National Association for the Education of Young Children.

Booren, L. M., Downer, J. T., \& Vitiello, V. E. (2012). Observations of children's interactions with teachers, peers, and tasks across preschool classroom activity settings. Early Education and Development, 23, 517-538. doi:10.1080/10409289.2010.548767

Brown, W. H., Odom, S. L., Li, S., \& Zercher, C. (1999). Ecobehavioral assessment in early childhood programs: A portrait of preschool inclusion. The Journal of Special Education, 33, 138-153.

Bryk, A. S., \& Raudenbush, S. W. (1992). Hierarchical linear models in social and behavioral research: Applications and data analysis methods (1st ed.). Newbury Park, CA: SAGE.

Bueno, M., Darling-Hammond, L., \& Gonzales, D. (2010, March). Education Reform Series. A matter of degree: Preparing teachers for the pre-k classroom. Washington, DC: PEW Center on the States. Retrieved from https://www.pewtrusts.org/ /media/legacy/uploadedfiles/wwwpewtrustsorg/reports/ pre-k_education/pkneducationreformseriesfinalpdf.pdf

Craig-Unkefer, L. A., \& Kaiser, A. P. (2002). Improving the social communication skills of at-risk preschool children in a play context. Topics in Early Childhood Special Education, 22, 3-13.

DeKlyen, M., \& Odom, S. L. (1989). Activity structure and social interactions with peers with developmentally integrated play groups. Journal of Early Intervention, 13, 342-352.

Diamond, K., Hong, S.-Y., \& Baroody, A. E. (2008). Early childhood curricular approaches to promote young children's social competence. In W. H. Brown, S. Odom, \& S. R. McConnell (Eds.), Social competence of young children: Risk, disability, and intervention (2nd ed., pp. 165-184). Baltimore, MD: Paul H. Brookes.

Diamond, K. E., \& Carpenter, E. S. (2000). Participation in inclusive preschool programs and sensitivity to the needs of others. Journal of Early Intervention, 23, 81-91. doi: 10.1177/10538151000 2300203

Diamond, K. E., \& Hong, S.-Y. (2010). Young children's decisions to include peers with physical disabilities in play. Journal of Early Intervention, 32, 163-177. doi: 10.1177/1053815110371332

Diamond, K. E., Hong, S.-Y., \& Tu, H. (2008). Context influences preschool children's decisions to include a peer with a physical disability in play. Exceptionality, 16, 141-155. doi: 10.10801093628 30802198328

Diamond, K. E., \& Tu, H. (2009). Relations between classroom context, physical disability and preschool children's inclusion decisions. Journal of Applied Developmental Psychology, 30, 75-81. doi: 10.1016/j.appdev.2008.10.008

Division for Early Childhood/National Association for the Education of Young Children. (2009). Early childhood inclusion: A joint statement of the Division for Early Childhood (DEC) and the National Association for the Education of Young Children (NAEYC). Chapel Hill: FPG Child Development Institute, The University of North Carolina at Chapel Hill.

Early, D. M., Bryant, D. M., Pianta, R. C., Clifford, R. M., Burchinal, M. R., Ritchie, S., \& Barbarin, O. (2006). Are teachers' education, major, and credentials related to classroom quality and children's academic gains in pre-kindergarten? Early Childhood Research Quarterly, 21, 174-195.

Fanger, S. M., Frankel, L. A., \& Hazen, N. (2012). Peer exclusion in preschool children's play: Naturalistic observations in a playground setting. Merrill-Palmer Quarterly, 58, 224-254.

Feldman, E. K., \& Matos, R. (2013). Training paraprofessionals to facilitate social interactions between children with autism and their typically developing peers. Journal of Positive Behavior Interventions, 15, 169-179. doi: 10.1177/1098300712457421 
Gasser, L., Malti, T., \& Buholzer, A. (2014). Swiss children's moral and psychological judgments about inclusion and exclusion of children with disabilities. Child Development, 85, 532-548. doi: 10.1111/cdev.12124

Giangreco, M. F., Edelman, S. W., Luiselli, T. E., \& MacFarland, S. Z. C. (1997). Helping or hovering? Effects of instructional assistant proximity on students with disabilities. Exceptional Children, 64, 7-18.

Goble, P., Hanish, L. D., Lynn Martin, C., Eggum-Wilkens, N. D., Foster, S. A., \& Fabes, R. A. (2016). Preschool contexts and teacher interactions: Relations with school readiness. Early Education and Development, 28, 64-79.

Guralnick, M. J. (1999). The nature and meaning of social integration for young children with mild developmental delays in inclusive settings. Journal of Early Intervention, 22, 70-86.

Guralnick, M. J. (2001). Early childhood inclusion. Baltimore, MD: Paul H. Brookes.

Guralnick, M. J., \& Bruder, M. B. (2016). Early childhood inclusion in the United States: Goals, current status, and future directions. Infants \& Young Children, 29, 166-177.

Guralnick, M. J., Gottman, J. M., \& Hammond, M. A. (1996). Effects of social setting on the friendship formation of young children differing in developmental status. Journal of Applied Developmental Psychology, 17, 625-651. doi: 10.1016/S0193-3973(96)90019-2

Harper, L. W., \& McCluskey, K. S. (2003). Teacher-child and child-child interactions in inclusive preschool settings: Do adults inhibit peer interactions? Early Childhood Research Quarterly, 18, 163-184.

Hartup, W. W., \& Abecassis, M. (2002). Friends and enemies. In P. K. Smith \& C. H. Hart (Eds.), Handbook of social development (pp. 285-306). Malden, MA: Blackwell.

Heidemann, S., \& Hewitt, D. (1992). Pathways to play: Developing play skills in children. St. Paul, MN: Redleaf Press.

Hong, S.-Y., Kwon, K., \& Jeon, H. (2014). Children's attitudes toward peers with disabilities: Associations with personal and parental factors. Infant and Child Development, 23, 170-193. doi: 10.1002/ icd.1826

Hsien, M., Brown, P. M., \& Bortoli, A. (2009). Teacher qualifications and attitudes toward inclusion. The Australasian Journal of Special Education, 33: 26-41. Retrieved from http://search.informit.com .au/documentSummary; $\mathrm{dn}=525003579785064$;res=IELHSS

Innocenti, M. S., Stowitschek, J. J., Rule, S., Killoran, J., Striefel, S., \& Boswell, C. (1986). A naturalistic study of the relation between preschool setting events and peer interaction in four activity contexts. Early Childhood Research Quarterly, 1, 141-153.

Jeon, H. J., \& Peterson, C. A. (2003). Pre-service teachers' attitudes toward inclusion: Early childhood education and elementary education programs. Journal of Early Childhood Teacher Education, 24, 171-179. doi: 10.1080/1090102030240306

Kemp, C., Kishida, Y., Carter, M., \& Sweller, N. (2013). The effect of activity type on the engagement and interaction of young children with disabilities in inclusive childcare settings. Early Childhood Research Quarterly, 28, 134-143. doi: 10.1016/j.ecresq.2012.03.003

Koller, D., Le Pouesard, M., \& Rummens, J. A. (2018). Defining social inclusion for children with disabilities: A critical literature review. Children \& Society, 32, 1-13. doi: 10.1111/chso.12223

Kontos, S. (1999). Preschool teachers' talk, roles, and activity settings during free play. Early Childhood Research Quarterly, 14, 363-382.

Kontos, S., Burchinal, M., Howes, C., Wisseh, S., \& Galinsky, E. (2002). An eco-behavioral approach to examining the contextual effects of early childhood classrooms. Early Childhood Research Quarterly, 17, 239-258. 
Kontos, S., Moore, D., \& Giorgetti, K. (1998). The ecology of inclusion. Topics in Early Childhood Special Education, 18, 38-48.

Kwon, K.-A., Hong, S.-Y., \& Jeon, H.-J. (2017). Classroom readiness for successful inclusion: Teacher factors and preschool children's experience with and attitudes toward peers with disabilities. Journal of Research in Childhood Education, 31, 360-378.

Li, J., Hestenes, L. L., \& Wang, Y. C. (2016). Links between preschool children's social skills and observed pretend play in outdoor childcare environments. Early Childhood Education Journal, 44, 61-68.

Maccoby, E. E. (1988). Gender as a social category. Developmental Psychology, 24, 755-765.

McCloskey, E. (2012). Inclusion as an instructional approach: Fostering inclusive writing communities in preschool classrooms. Journal of Early Childhood Literacy, 12, 46-67. doi: 10.1177/14687984 11416790

McCormick, L., Noonan, M. J., \& Heck, R. (1998). Variables affecting engagement in inclusive preschool classrooms. Journal of Early Intervention, 21, 160-176.

McGaha, C. G., \& Farran, D. C. (2001). Interactions in an inclusive classroom: The effects of visual status and setting. Journal of Visual Impairment $\mathcal{E}$ Blindness, 95, 80-94.

McWilliam, R. A., Scarborough, A. A., \& Kim, H. (2003). Adult interactions and child engagement. Early Education and Development, 14, 7-27.

Odom, S. L., Buysse, V., \& Soukakou, E. (2011). Inclusion for young children with disabilities: A quarter century of research perspectives. Journal of Early Intervention, 33, 344-357. doi: 10.1177/ 1053815111430094

Odom, S. L., Favazza, P. C., Brown, W. H., \& Horn, E. M. (2000). Approaches to understanding the ecology of early childhood environments for children with disabilities. In F. Symons (Ed.), Behavioral observation: Technology and applications in developmental disabilities (pp. 193-214). Baltimore, MD: Paul H. Brookes.

Odom, S. L., \& Peterson, C. (1990). Ecobehavioral analysis of early education/specialized classroom settings and peer social interaction. Education $\mathcal{E}$ Treatment of Children, 13, 316-331.

Odom, S. L., Vitztum, J., Wolery, R., Lieber, J., Sandall, S., Hanson, M. J., et al. (2004). Preschool inclusion in the United States: A review of research from an ecological systems perspective. Journal of Research in Special Educational Needs, 43(3), 17-49.

Odom, S. L., Zercher, C., Li, S., Marquart, J. M., Sandall, S., \& Brown, W. H. (2006). Social acceptance and rejection of preschool children with disabilities: A mixed-method analysis, Journal of Educational Psychology 98, 807-823. doi: 10.1037/0022-0663.98.4.807

Peck, C., Carlson, P., \& Helmstetter, E. (1992). Parent and teacher perceptions of outcomes for typically developing children enrolled in integrated early childhood programs: A statewide survey. Journal of Early Intervention, 16, 53-63. doi: 10.1177/105381519201600105

Powell, D. R., Burchinal, M. R., File, N., \& Kontos, S. (2008). An eco-behavioral analysis of children's engagement in urban public school preschool classrooms. Early Childhood Research Quarterly, 23, 108-123. doi: 10.1016/j.ecresq.2007.04.001

Rubin, K. H. (2001). The Play Observation Scale. College Park: The Center for Children, Relationships and Culture, University of Maryland.

Schuler, A. L., \& Wolfberg, P. J. (2000). Promoting peer play and socialization: The art of scaffolding. In B. M. Prizant (Ed.), Autism spectrum disorders: A transactional developmental perspective (pp. 251279). Baltimore, MD: Paul H. Brookes.

Shim, S.-Y., Herwig, J. E., \& Shelley, M. (2001). Preschoolers' play behaviors with peers in classroom and playground settings. Journal of Research in Childhood Education, 15, 149-163. doi: 10.1080/02568 540109594956 
Sontag, J. C. (1997). Contextual factors influencing the sociability of preschool children in integrated and segregated classrooms. Exceptional Children, 63, 389-405.

Tsao, L., Odom, S. L., Buysse, V., Skinner, M., West, T., \& Vitztum-Komanecki, J. (2008). Social participation of children with disabilities in preschool programs: Program typology and ecological features. Exceptionality, 16, 125-140. doi: 10.1080/09362830802198203

U.S. Department of Education. (2013). Digest of education statistics: 2012. Retrieved from http://nces.ed .gov/programs/digest/d12/guide.asp

Verhaegh, J., Soute, I., Kessels, A., \& Markopoulos, P. (2006, June 6-9). On the design of Camelot, an outdoor game for children. In Proceedings of the 2006 conference on interaction design and children (pp. 9-16). New York, NY: ACM. doi: 10.1145/1139073.1139082

Vygotsky, L. S. (1978). Mind in society: The development of higher psychological processes. Cambridge, MA: Harvard University Press.

Wei, R. C., Darling-Hammond, L., \& Adamson, F. (2010). Professional development in the United States: Trends and challenges. Dallas, TX: National Staff Development Council.

Yu, S., Ostrosky, M. M., \& Fowler, S. A. (2012). Measuring young children's attitudes toward peers with disabilities: Highlights from the research. Topics in Early Childhood Special Education, 32, 132142. doi: $10.1177 / 0271121412453175$ 